\title{
The Relationship of Dieting Severity and Bulimic Behaviors to Alcohol and Other Drug Use in Young Women
}

\author{
Dean Krahn \\ Department of Psychiatry \\ University of Wisconsin-Madison Medical School \\ William S. Middleton Memorial Veterans Hospital \\ Candace Kurth \\ University of Michigan \\ School of Public Health \\ Mark Demitrack \\ Department of Psychiatry \\ University of Michigan Medical School \\ Adam Drewnowski \\ Department of Psychiatry \\ University of Michigan Medical School \\ University of Michigan \\ School of Public Health
}

\begin{abstract}
Patients with bulimia nervosa frequently have problems with alcoholism and other substance abuse. The goal of this study was to assess whether this relationship between eating abnormalities and substance abuse extends to subthreshold levels of dieting and substance use. A self-administered questionnaire assessing dieting and substance use (alcohol, cigarettes, and marijuana) was completed by 1,796 women prior to their freshman year in college. Using a scale derived from DSM-III-R criteria for bulimia nervosa and previous research in this population, subjects were categorized as nondieters, casual, intense, severe, at-risk, or bulimic dieters. The relationship between the dieting-severity category and frequency and intensity of alcohol use and frequency of marijuana and cigarette use was assessed. DSM-III-R criteria for bulimia nervosa were met by $1.6 \%$ of the women. Only $13.8 \%$ of these women were nondieters. Increasing dieting severity was positively associated with increasing prevalence of alcohol, cigarette, and marijuana use and with increasing frequency and intensity of alcohol use. The bulimic and at-risk dieters were similar in their alcohol and drug use. The relationship between eating disorders and alcoholism and other substance abuse noted in clinical populations extends in a continuous, graded manner to subthreshold levels of dieting and substance use behaviors. Dieting-related attitudes and behaviors in young women may be related to increased susceptibility to alcohol and drug abuse.
\end{abstract}

This study was supported by NIDA grant R01-DA 06791-01.

Correspondence and requests for reprints should be sent to Dean Krahn, William S. Middleton Memorial Veterans Hospital, 2500 Overlook Terrace, Madison, WI 53705. 
Numerous studies have demonstrated a high prevalence of alcohol and other drug abuse in patients with clinically evident eating disorders, including bulimia nervosa and anorexia nervosa (Beary, Lacey, \& Merry, 1986; Beaumont, George, \& Smart, 1976; Brisman \& Siegel, 1984; Casper, Eckert, Halmi, Goldberg, \& Davis, 1988; Crisp, 1968; Eckert, Goldberg, Halmi, Casper, \& Davis, 1982; Garfinkel, Moldofsky, \& Garner, 1980; Hatsukami, Eckert, Mitchell, \& Pyle, 1984; Jonas, Gold, Sweeney, \& Pottash, 1987; Jones, Cheshire, \& Moorhouse, 1985; Leon, Carroll, Chernyk, \& Finn, 1985; Marcus \& Halmi, 1989; Mitchell, Hatsukami, Eckert, \& Pyle, 1985; Pyle, Mitchell, \& Eckert, 1981; Strober, Salkin, Burroughs, \& Morrell, 1982; Walsh, 1985; Weiss \& Ebert, 1983). For example, $49 \%$ of a sample of 275 bulimia nervosa patients reported using alcohol several times per week or more (Mitchell et al., 1985). Pyle et al. (1981) and Beary et al. (1986) reported clinically significant substance abuse problems in $24 \%$ and $50 \%$, respectively, of their patients with bulimia nervosa. Conversely, cross-sectional studies have shown a high prevalence of eating disorders in female patients presenting with substance abuse, including alcohol and cocaine abuse (Jonas et al., 1987; Marcus \& Halmi, 1989). Thus, it is clear that there is an association between clinical eating disorders, especially bulimia nervosa, and clinically significant substance abuse.

Far fewer studies have examined whether subthreshold eating disorders [i.e., dieting behaviors and/or attitudes that do not fulfill DSM-III-R (American Psychiatric Association, 1987) criteria for eating disorders] also are associated with increased use of alcohol and other drugs. Two studies have shown a positive association between bulimic behaviors and substance use in high school and college students (Frank, Serdula, \& Abel, 1987; Killen et al., 1987). Dieting and binge drinking were positively associated in a nationwide assessment of behavioral risk factors in adults (Bradstock et al., 1988). However, the instruments used in these studies did not intensively assess the range of severity of bulimic behaviors or whether $D S M-I I I-R$ criteria for bulimia nervosa were likely to be fulfilled. As we have previously noted that bulimia nervosa only represents one end of a continuum of behaviors and attitudes related to the pursuit of thinness in young women (Drewnowski, Yee, \& Krahn, 1989), we thought that this was an important shortcoming. We suggest that the high coprevalence of eating disorders with substance abuse extends to subthreshold levels of these two serious conditions. If so, this relationship is extremely important. For example, whereas $D S M-I I I-R$-defined bulimia nervosa is present in only $1-3 \%$ of college women (Drewnowski, Yee, \& Krahn, 1988; Schotte \& Stunkard, 1987), bulimic behaviors and subthreshold levels of eating disorders are far more prevalent. Indeed, estimates of lifetime prevalence of binge eating in young women range from $19 \%$ in college freshman women to $71 \%$ in a sample of college students averaging 22 years of age (Pyle, Halvorson, Neuman, \& Mitchell, 1986; Schotte \& Stunkard, 1987). Previous surveys of college freshman women at the same school indicate that over $80 \%$ display at least some form of dieting behavior or attitudes (Drewnowski et al., 1989). Others also have found high rates of similar behaviors and attitudes in high school and college populations (Pyle, Mitchell, Eckert, \&c 
Halvorson, 1983; Rosen \& Gross, 1987; Striegel-Moore, Silberstein, Frensch, \& Rodin, 1989).

In order to clarify the relationship between substance use and dieting across a wide range of severity, we surveyed incoming freshman women at a major midwestern university. We hypothesized that dieting severity would be continuously related to the prevalence, frequency, and intensity of substance use in a graded manner such that subjects who reported symptoms that fulfilled DSM-III-R criteria for bulimia nervosa would report the highest levels of substance use; those who reported subthreshold levels of dieting behaviors would report intermediate levels of substance use; and those who reported little or no dieting would report the lowest levels of substance use.

\section{METHOD}

All women attending a freshman orientation at a major midwestern university were invited to participate. Subjects completed a self-administered questionnaire regarding weight, dieting, exercise, purging, weight-related attitudes and substance use (cigarettes, alcohol, and marijuana). Questions were obtained from earlier studies of dieting behavior by Drewnowski et al. (1989) and the Monitoring the Future Study (MTF), a national, ongoing assessment of substance use patterns in high school seniors and young adults (Johnston, Bachman, \& O'Malley, 1990). Participation in the study was voluntary and anonymous. The protocol was approved by the Institutional Review Board. Questionnaires were completed by 1,796 women, a $90 \%$ response rate.

Frequencies of alcohol, cigarette, and marijuana use over the last month, past year and lifetime were assessed, along with two indicators of heavy drinking [i.e., the frequencies of having five or more drinks in a row (question from MTF) and of drinking enough alcohol to get "buzzed" (question modified from MTF)]. For example, a subject would indicate whether she had had alcohol to drink on $0,1-$ $2,3-5,6-9,10-19,20-39$, or 40 or more occasions in the past month. Questions regarding dependence were not included due to time constraints. Subjects also rated their frequency of depressed mood on a 5-point categorical scale ranging from never to always.

Six mutually exclusive dieting-severity categories were defined prior to data analyses. The categories were based on DSM-III-R criteria for bulimia nervosa and results of previous studies (Drewnowski et al., 1988, 1989). The DSM-III-R diagnostic schema for bulimia nervosa specifies criteria in three domains: bingeeating behavior, purging and excessive dieting, and dysfunctional attitudes. Accordingly, the bulimic group (1.6\% of the sample) consisted of women who reported:

1. Binge eating two or more times per week for the past $\mathbf{3}$ months.

2. Purging or excessive dieting (one or more of the following behaviors: use of laxatives, diuretics, vomiting, fasting, or diet pills at a frequency of several 
times a month or more; dieting at a frequency of often or always; and/or daily intensive exercise).

3. Dysfunctional attitudes (one or more of the following attitudes at a frequency of often or always: lack of control when eating, fear of gaining weight, and dissatisfaction with body shape).

At-risk dieters (16.6\%) met $D S M-I I I-R$ criteria for two of the three domains. Severe dieters $(22.3 \%)$ met $D S M-I I I-R$ criteria for binging or purging and excessive dieting, and had subthreshold symptoms in at least one of the other two domains. Intense dieters (12.4\%) met DSM-III-R criteria for dysfunctional attitudes and/or infrequently engaged in purging and/or reported binging behavior. Casual dieters $(33.2 \%)$ reported no binging or purging, and occasional dieting and/or minimal dysfunctional attitudes. Nondieters $(13.8 \%)$ reported no binging, dieting, purging, or dysfunctional attitudes.

The relationship between dieting severity and substance use, for each of the three substances, was similar for all time frames (lifetime, past year, and past month). Therefore, we present only "past month" substance use data.

Data were coded and double-entered. Analyses were conducted using BMDP (BMDP Statistical Software, Inc., 1988). Kruskal-Wallis analysis of variance and pairwise multiple comparison tests were used to test for group differences for continuous variables. Cochran's test for linear trend and odds ratios were used to assess the relationship between dieting severity and prevalence of substance use. Casual dieters were the reference group for calculating odds ratios because they comprised the largest proportion of the sample. Gamma statistics were calculated to assess the direction and significance of the relationship between frequency of substance use and dieting severity. In the analyses of the relationship between dieting severity and frequency of heavy drinking or getting buzzed while drinking, only subjects who reported some drinking in the past month were included. Comparison of the observed prevalence of alcohol use in those subjects with frequency of depressed mood rated as often or always and those subjects with less frequent depressed moods with the expected prevalence of drinking were done within each dieting-severity category using the chi-square statistic.

\section{RESULTS}

Subject characteristics for each group are presented in Table 1. As expected, weights and desired weight loss differed across the dieting-severity groups such that the groups that dieted more severely weighed more and wanted to lose more weight.

Prevalence of alcohol use was positively associated with dieting severity. The prevalence of drinking during the past month for each of the dieting-severity categories is presented in Table 2 . The prevalence of alcohol use increased across the entire range of dieting severity from $43.9 \%$ for nondieters to approximately $72 \%$ for at-risk and bulimic dieters. Nondieters were significantly less likely than 
Table 1. Subject Characteristics by Dieting-Severity Category

\begin{tabular}{|c|c|c|c|c|c|c|c|c|c|c|}
\hline \multirow{2}{*}{$\begin{array}{l}\text { Dieting-Severity } \\
\text { Category }\end{array}$} & \multirow[b]{2}{*}{$n$} & \multirow[b]{2}{*}{ (\%) } & \multicolumn{2}{|c|}{ Age } & \multicolumn{2}{|c|}{$\begin{array}{l}\text { Height in } \\
\text { Inches }\end{array}$} & \multicolumn{2}{|c|}{$\begin{array}{l}\text { Weight in } \\
\text { Pounds }\end{array}$} & \multicolumn{2}{|c|}{$\begin{array}{l}\text { Desired Weight } \\
\text { Change in } \\
\text { Pounds }\end{array}$} \\
\hline & & & $M$ & (SD) & $M$ & (SD) & $M$ & $(S D)$ & $M$ & $(S D)$ \\
\hline Bulimic & 29 & (1.6) & 17.7 & $(0.5)$ & 64.7 & (2.5) & 129.4 & (14.4) & -11.8 & (7.1) \\
\hline At-Risk & 298 & (16.6) & 17.7 & (0.5) & 64.7 & (2.6) & 130.6 & (19.2) & -12.4 & (11.4) \\
\hline Severe & 401 & (22.3) & 17.7 & $(0.8)$ & 64.8 & (2.8) & 129.8 & (19.4) & -9.8 & $(9.5)$ \\
\hline Intense & 223 & (12.4) & 17.7 & $(0.6)$ & 65.3 & (2.7) & 126.0 & $(18.8)^{\mathrm{a}}$ & -5.9 & $(12.0)^{b}$ \\
\hline Casual & 598 & (33.2) & 17.7 & $(0.7)$ & 64.9 & (2.7) & 125.2 & $(17.0)^{\mathrm{a}}$ & -6.4 & $(7.7)^{\mathrm{b}}$ \\
\hline Nondieting & 247 & (13.8) & 17.7 & (1.1) & 64.9 & (2.9) & 116.0 & $(16.7)^{c}$ & -0.8 & $(6.9)^{b, d}$ \\
\hline
\end{tabular}

aCasual and intense groups together weighed less than the severe, at-risk, and bulimic groups ( $z$ values $>4.18, p<.01$ ).

bNondieters desired less weight loss than casual and intense groups who, in turn, desired less weight loss than the severe, at-risk, and bulimic groups ( $z$ values $>4.07, p<.01$ ).

cKruskal-Wallis $H$ test $=127, d f=5, p<.001$ indicating differences between groups in weight; nondieting group weighs significantly less than all other groups $(z$ values $>4.35, p<.01)$.

dDifferences in desired weight loss between groups were significant (Kruskal-Wallis $H$ test $=353$, $d f=5, p<.01$ ).

casual dieters to have consumed alcohol, whereas the severe and at-risk groups were significantly more likely to have used alcohol. The association between alcohol consumption and dieting severity was not confounded by cigarette or marijuana use. Annual prevalence of alcohol use rates were: bulimic $=93 \%$; atrisk $=91 \%$; severe $=84 \%$; intense $=87 \%$; casual $=80 \%$; and nondieters $=$ $72 \%$. Lifetime prevalence of alcohol use rates were: bulimic $=97 \%$; at-risk $=$ $95 \%$; severe $=93 \%$; intense $=94 \%$; casual $=89 \%$; and nondieters $=86 \%$.

The frequency of alcohol use also was positively related to dieting severity (Figure 1). As dieting severity increased, the reported number of occasions of alcohol consumption increased. The bulimic and at-risk groups were similar in their frequency of alcohol use, with more than $40 \%$ of the subjects using alcohol on an approximately weekly or more frequent basis. In contrast, less than $20 \%$ of the nondieters and less than $30 \%$ of casual dieters consumed alcohol at that

Table 2. Prevalence of Drinking Alcohol, Bivariate Odds Ratios and 95\% Confidence Intervals for Past Month's Drinking

\begin{tabular}{lccc}
\hline $\begin{array}{l}\text { Dieting-Severity } \\
\text { Categories }\end{array}$ & $\begin{array}{c}\text { Prevalence of } \\
\text { Drinking (\%) }\end{array}$ & $\begin{array}{c}\text { Bivariate } \\
\text { Odds Ration, }\end{array}$ & 95\% CIb \\
\hline Bulimic & 72.0 & 1.92 & $0.85-4.36$ \\
At-Risk & 71.7 & 1.85 & $1.37-2.50$ \\
Severe & 65.0 & 1.33 & $1.02-1.73$ \\
Intense & 61.8 & 1.18 & $0.86-1.63$ \\
Casual & 57.7 & - & - \\
Nondieting & 43.9 & 0.56 & $0.43-0.78$ \\
\hline
\end{tabular}

Test for linear trend, $x^{2}=46.5, p<.0001$.

bCasual dieters used as reference group. 


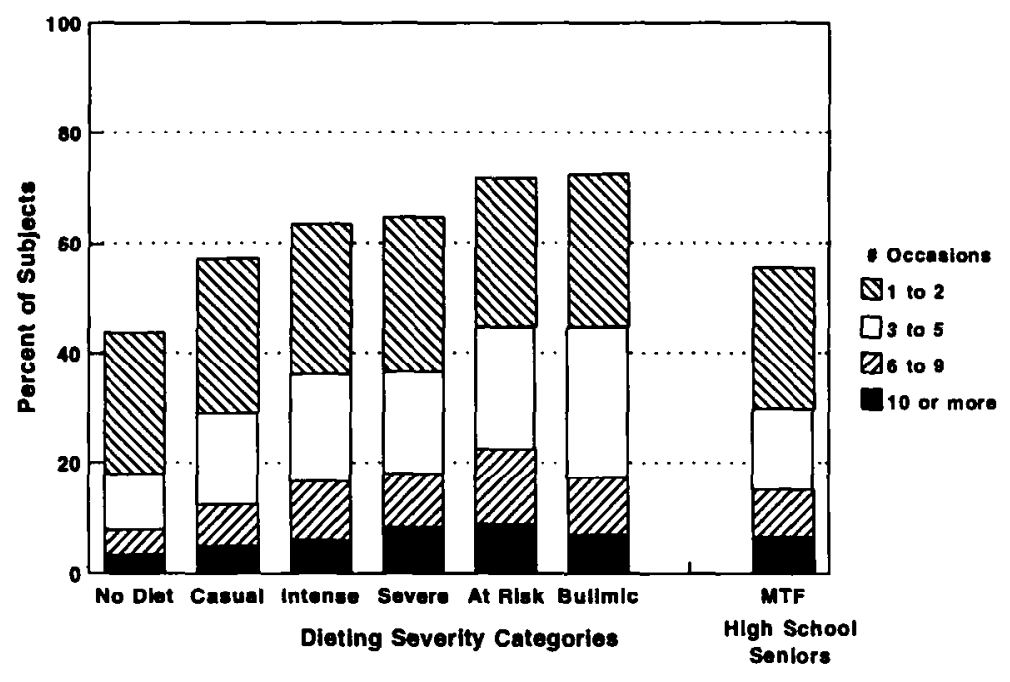

"Never drinking" category not shown.

Figure 1. The percentage of subjects in each dieting-severity category who reported each frequency of alcohol use over the last month is shown. The relationship between dieting-severity categories and frequency of alcohol use categories is significant $(\gamma=.21, t=8.24, p<.001)$. Data on the same question from the 1989 MTF study (Johnston et al., 1990) obtained from a national sample of high school senior girls with probable or definite plans to graduate from a 4-year college are included for comparison.

frequency. Thus, dieting severity was related not only to the prevalence of alcohol use but also to the frequency of alcohol consumption.

The frequency of heavy drinking (consuming five or more drinks in a row) in the past 2 weeks was positively related to dieting severity (Figure 2). As dieting severity increased, the reported number of occasions of heavy drinking increased. Almost one fifth of the bulimic and at-risk subjects, compared to 1 in 20 nondieters, reported drinking five or more drinks in a row on a weekly basis. Similarly, the frequency of drinking enough to alter their mental state also was positively related to dieting severity (Figure 3). Fifty to sixty percent of the subjects in the at-risk and bulimic groups achieved a change in mental state on most or all drinking occasions, compared to approximately half that percentage in the lower two dieting-severity groups. Thus, dieting severity was positively related to the intensity of alcohol use.

Prevalence of smoking was positively associated with dieting severity (test for linear trend $=25.1, p<.001$ ). The prevalence of cigarette smoking in the past month and bivariate odds ratios for each dieting-severity category are presented in Table 3. Nondieters were significantly less likely than casual dieters to have smoked $(p<.05)$ whereas the intense and at-risk groups were significantly more likely to have smoked $(p<.05)$. The lifetime prevalence of smoking occasionally to regularly in the past or currently, increased across the entire range of dieting 


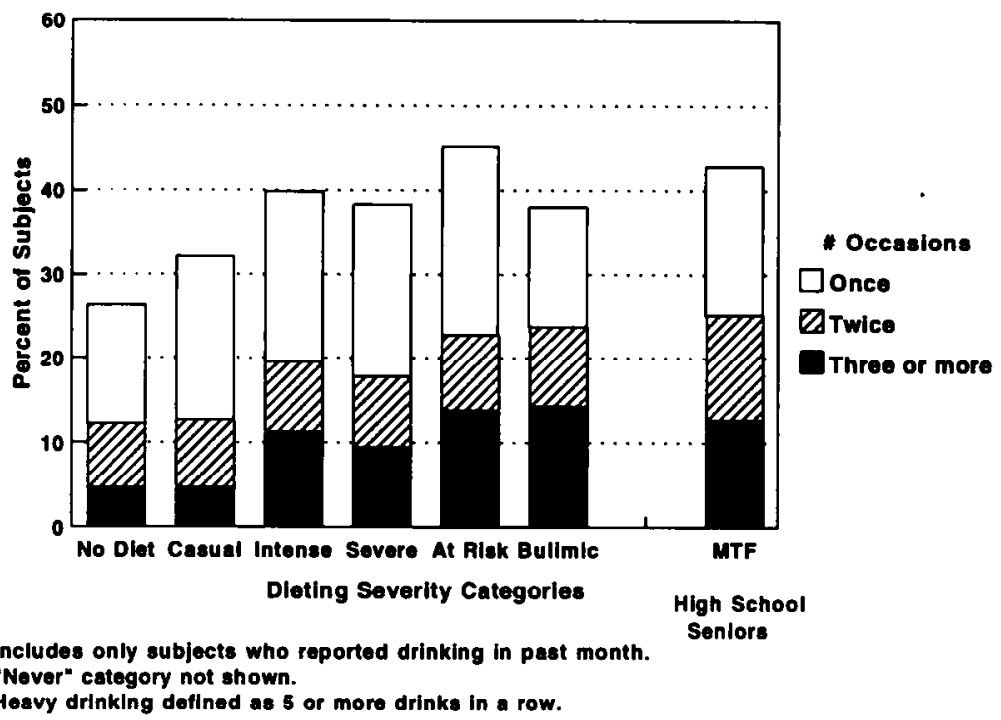

Figure 2. The frequency of drinking heavily (i.e., five drinks or more in a row) in the past 2 weeks is shown for subjects in each dieting-severity category. Increasing severity of dieting is significantly related to increasing frequency of heavy drinking $(\gamma=$ $.16 ; t=4.10, p<.001$ ). Data on the same question from the 1989 MTF study (Johnston et al., 1990) obtained from a national sample of high school senior girls with probable or definite plans to graduate from a 4-year college are included for comparison.

severity $(41.3 \%$ of bulimic, $32.6 \%$ of at-risk, $27.4 \%$ of severe, $25.2 \%$ of intense, $19.8 \%$ of casual, and $12.5 \%$ of nondieters).

The prevalence of marijuana use in the past month and bivariate odds ratios for each dieting-severity category are presented in Table 4. The at-risk and bulimic dieters were significantly more likely to have used marijuana $(p<.05)$. Annual and lifetime rates for marijuana use were: bulimics $=37 \%, 41 \%$; at-risk $=27 \%, 37 \%$; severe $=15 \%, 23 \%$; intense $=15 \%, 28 \%$; casual $=13 \%, 20 \%$; and nondieters $=12 \%, 17 \%$.

Table 3. Prevalence of Smoking in Past Month, Bivariate Odds Ratios and $95 \%$ Confidence Intervals.

\begin{tabular}{lccc}
\hline $\begin{array}{l}\text { Dieting-Severity } \\
\text { Categories }\end{array}$ & $\begin{array}{c}\text { Prevalence of } \\
\text { Smoking (\%) }\end{array}$ & $\begin{array}{c}\text { Bivariate } \\
\text { Odds Ratio=, }\end{array}$ & $\mathbf{9 5 \% ~ C I \mathbf { b }}$ \\
\hline Bulimic & 20.7 & 2.47 & $0.99-6.16$ \\
At-Risk & 18.6 & 2.17 & $1.45-3.23$ \\
Severe & 11.8 & 1.25 & $0.83-1.90$ \\
Intense & 15.7 & 1.77 & $1.13-2.78$ \\
Casual & 9.5 & - & - \\
Nondieting & 4.9 & 0.49 & $0.26-0.92$ \\
\hline
\end{tabular}

Test for linear trend, $x^{2}=25.1, p<.001$.

bCasual dieters used as reference group. 


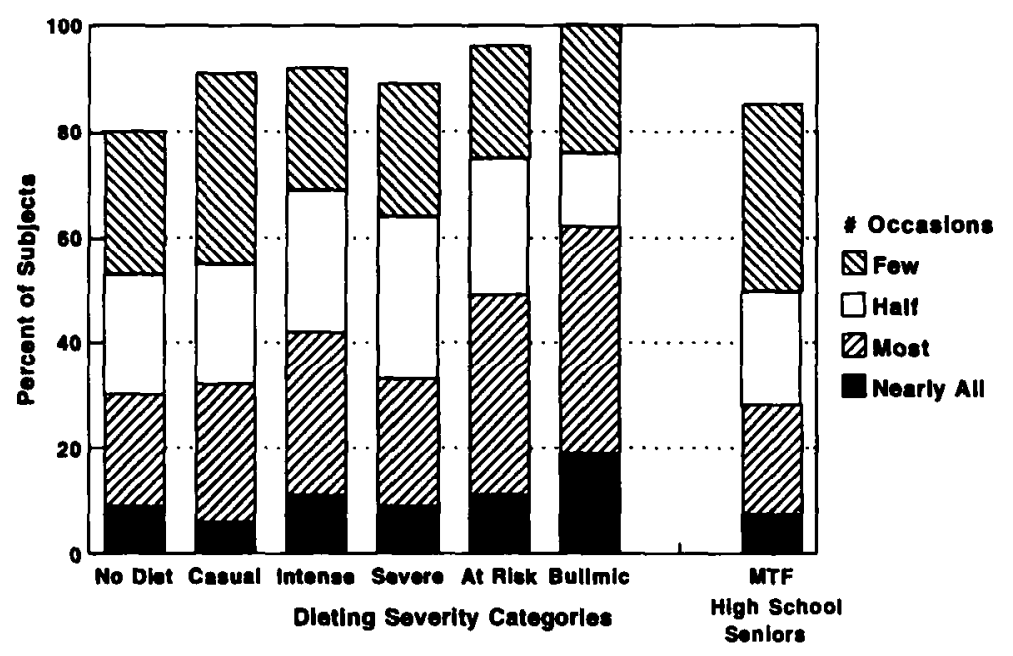

Includes only subjects who reported drinking in past month.

"Nover" category not shown.

Figure 3. The frequency of drinking enough alcohol to get buzzed is shown for subjects in each dieting-severity category. Increasing severity of dieting is significantly related to increasing frequency of getting buzzed when drinking alcohol $(\gamma=.18, t=$ $5.61, p<.001$ ). Data on the question "How often do you drink enough to get pretty high (as opposed to buzzed)?" from the 1989 MTF study (Johnston et al., 1990) obtained from a national sample of high school senior girls with plans to graduate from a 4-year college are included for comparison.

It is important to note that virtually all smokers and marijuana users consumed alcohol, making it impossible to assess independent relationships with dieting severity. Of interest is that the more severe dieters were more likely to abuse more than one substance $(\gamma=.26, t=7.4, p<.001)$. Within dietingseverity categories, the observed prevalence of alcohol use in those subjects with frequent depressed mood and those subjects with infrequent depressed moods did not differ from expected frequencies (chi-squares all nonsignificant, data not

Table 4. Prevalence of Marijuana Use in Past Month, Bivariate Odds Ratios and $95 \%$ Confidence Intervals.

\begin{tabular}{lccc}
\hline $\begin{array}{l}\text { Dieting-Severity } \\
\text { Categories }\end{array}$ & $\begin{array}{c}\text { Prevalence of } \\
\text { Marijuana Use (\%) }\end{array}$ & $\begin{array}{c}\text { Bivariate } \\
\text { Odds Ratio,b }\end{array}$ & 95\% CIb \\
\hline Bulimic & 14.8 & 3.09 & $1.06-9.00$ \\
At-Risk & 9.7 & 1.91 & $1.13-3.24$ \\
Severe & 7.2 & 1.37 & $0.81-2.31$ \\
Intense & 5.3 & 1.12 & $0.58-2.19$ \\
Casual & 5.4 & - & - \\
Nondieting & 6.8 & 1.29 & $0.69-2.41$ \\
\hline
\end{tabular}

a Test for linear trend, Pearson $\chi^{2}=9.2$, n.s.

bCasual dieters used as reference group. 
shown). Also, within dieting-severity categories, there was no difference in the prevalence of alcohol use between binge-eating and nonbinge-eating subjects.

\section{DISCUSSION}

These data show that the relationship between dieting behaviors and increased substance use is not limited to the categories of clinically diagnosable bulimia nervosa and alcoholism, but also extends across the wide range of less severe, but far more frequent levels of dieting and substance use observed in a large population of incoming college women. These results support the hypothesis that there is a positive, continuous relationship between dieting severity and the prevalence, frequency, and intensity of alcohol use. Hence, the most frequent and intense alcohol use was reported by the bulimic and at-risk dieting groups; an intermediate level of alcohol use was reported by the severe and intense groups; and the lowest alcohol use was reported by the nondieters. The prevalences of cigarette and marijuana use also were positively related to dieting severity. Furthermore, the more severe dieters were more likely to use multiple substances, a pattern that may be indicative of the future development of clinically significant substance use problems (Jessor \& Jessor, 1977; Kandell \& Logan, 1984).

Patients with bulimia nervosa have prevalence rates for alcohol abuse and/or dependence ranging as high as 50\% (Beary et al., 1986; Mitchell et al., 1985; Pyle et al., 1981). Considering that those subjects who were categorized as at-risk (16.6\% of the sample) behaved similarly in their use of alcohol and other drugs to those subjects reporting behaviors and attitudes consistent with bulimia nervosa (1.6\%), we suggest that the at-risk group of dieters is also at increased risk for the development of chemical dependency. It should be noted that the more severe dieting groups not only consumed alcohol frequently, but also got buzzed more often when drinking. In other words, the differences among dietingseverity groups in the qualitative use of alcohol as a mood-altering substance were even larger than indicated by the simple frequency of alcohol use. Intermediate levels of dieting, which we categorized as severe or intense, also were associated with increased substance use. Finally, this pattern occurred even in casual dieters, who used alcohol more than nondieters.

The associations found here are unlikely to be due to distortions of data collection. Our response rate was $90 \%$, making biased self-selection by respondents unlikely. The self-reported frequency of alcohol consumption is similar to national data for a group of high school senior girls with plans to graduate from a 4-year college (see Figures 1-3; Johnston et al., 1990). The prevalence of presumed bulimia nervosa in this study is very similar to the Schotte and Stunkard (1987) report of $1.3 \%$ in their sample of college women and to a previous report of $2.9 \%$ in another class at the same university (Drewnowski et al., 1988). The prevalence of binge eating in Drewnowski et al.s (1988) study (25.5\% of the sample) is close to the $19.9 \%$ prevalence reported by Pyle et al. (1986) in a survey of freshman college women. Finally, the distribution of sub- 
jects into dieting-severity categories is similar to that observed in a previous study of freshman women (Drewnowski et al., 1989).

Two major hypotheses have been invoked to explain the increased substance abuse in women with eating disorders. The first suggests that the increased substance use reflects an underlying "addictive" personality. The other major hypothesis emphasizes food deprivation as a primary event causing alterations in the function of central nervous system reward pathways such that increased use of drugs becomes more likely. Although neither hypothesis is sufficient to explain the phenomenon of comorbidity of eating and substance use disorders, we believe that these data lend support to the idea of food deprivation as a primary event and argue against the hypothesis of a preexisting addictive personality. For instance, the increased use of a wide variety of substances was not restricted to subjects who were binge eating frequently, but occurred continuously across a spectrum of food-restricting behavior. It seems unlikely that an addictive personality style would directly correlate with severity of dieting across the entire population of young women. Obviously, these comments regarding addictive personality as causes of eating disorder and substance use disorder comorbidity are speculative as we did not measure personality traits. Furthermore, other factors (probably including inherited and developmental influences) besides food deprivation must determine substance abuse in dieting women because most women who diet do not develop significant substance abuse.

Food deprivation potently stimulates drug self-administration in laboratory animals as well as in humans (Carroll \& Meisch, 1984; Franklin, Schiele, Brozek, \& Keys, 1948). Food deprivation increases the self-administration of drugs by both intravenous and oral routes and in both rats and rhesus monkeys (Carroll, 1982; Carroll, France, \& Meisch, 1979; Carroll \& Meisch, 1980, 1984). The selfadministration of a wide variety of drugs including alcohol, barbituates, opiates, cocaine, amphetamine, and phencyclidine increases with food deprivation (Carroll \& Meisch, 1984). Various forms of food restriction are standard methods for establishing drug use in animals (Stewart \& Grupp; 1984). Thus, food deprivation increases the acquisition of the drug as a reinforcer as well as the consumption of drugs already established as reinforcers. Interestingly, food-deprived humans also may increase their drug intake (Franklin et al., 1948; Hanna \& Hornick, 1977). Food deprivation also increases the intake of sweet solutions (Hursh \& Beck, 1971) and fat (Reed, Contreras, Maggio, Greenwood, \& Rodin, 1988 ) in rats. Increased intakes of alcohol, drugs, and sweet, high-fat foods due to food deprivation resemble the alcohol and drug use and binge eating seen in bulimics. It is possible that the processes mediating preferences for high-fat diets and sweet tastes is related to the mechanism mediating preference for alcohol because rats that prefer sweet tastes or high-fat diets drink more alcohol than rats that prefer less sweet or low-fat diets, and rat strains that prefer alcohol also prefer high-fat diets (Forsander, 1988; Gosnell \& Krahn, 1992; Krahn \& Gosnell, 1991). Our data are consistent with the hypothesis that self-deprivation of food (i.e., dieting) increases susceptibility to frequent drug use. However, it is unknown whether the caloric deprivation, psychological stress of attempting to self-deprive, or other factors are critical in this relationship. 
Although we have hypothesized that food deprivation results in increased drug use in dieting women, this causal relationship between dieting and substance use cannot be determined from our cross-sectional study. We also cannot rule out the possibility that both of these behaviors are the consequence of a primary disturbance such as depression. However, no relationship between frequency of self-reported depressed mood and alcohol intake within dieting subcategories was observed. Other possible explanations include:

1. That dieting and certain alcohol and drug use behaviors are both culturally supported for adolescent women and that this merely shows that a group of women who are susceptible to cultural pressures for one set of behaviors are equally susceptible to cultural pressures for another set of behaviors.

2. That there is another primary or antecedent factor explaining both behaviors such as aberrant family dynamics or genetics or a history of traumas.

3. That both the changes in dieting patterns and the use of alcohol represent escapes from self-awareness or reality (Heatherton \& Baumeister, 1991).

None of these hypotheses were examined or testable in this study. More intensive and, especially, longitudinal studies will be needed.

Although this study was not designed to assess alcohol or other drug dependence, it is interesting that those subjects who drank most frequently also displayed other features consistent with abuse such as more frequent heavy drinking and more often experiencing mental changes when drinking. Whereas this increased rate of changing mental state via alcohol use could be explained by drinking while food-deprived or dehydrated, this would not explain the increased frequency of heavy drinking.

In summary, our findings support the hypothesis that chronic dieting may serve as an important factor in the development of substance abuse in young women. Specifically, we suggest that chronic efforts at food deprivation in humans should be considered as a factor that not only predisposes to binge eating, but also to increased substance use and/or abuse. However, the possibility that a primary factor causes both the dieting and alcohol use clearly has not been ruled out or even examined in this study. It may be appropriate to target dieting as a risk behavior in drug abuse programs for women.

\section{REFERENCES}

American Psychiatric Association (1987). Diagnostic and statistical manual of mental disorders (3rd ed., rev. ed.). Washington, DC: Author.

Beary, M.D., Lacey, J.H., \& Merry, J. (1986). Alcoholism and eating disorders in women of fertile age. British Joumal of Addiction, 81, 685-689.

Beaumont, P.J.W., George, G.C.W., \& Smart, D.E. (1976). Dieters and vomiters and purgers in anorexia nervosa. Psychological Medicine, 6, 617-622.

Bradstock, K., Forman, M.R., Binkin, N.J., Gentry, E.M., Hogelin, G.C., Williamson, D.F., \& Trowbridge, F.L. (1988). Alcohol use and health behavior lifestyles among U.S. women: The behavioral risk factor surveys. Addictive Behaviors, 13, 61-71. 
Brisman, J., \& Siegel, M. (1984). Bulimia and alcoholism: Two sides of the same coin? Journal of Substance Abuse Treatment, 1, 113-118.

Carroll, M.E. (1982). Rapid acquisition of oral phencyclidine self-administration in food-deprived and food-satiated rhesus monkeys: Concurrent phencyclidine and water choice. Pharmacology, Biochemistry, and Behavior, 17, 341-346.

Carroll, M.E., France, C.P., \& Meisch, R.A. (1979). Food deprivation increases oral and intravenous drug intake in rats. Science, 205, 319-321.

Carroll, M.E., \& Meisch, R.A. (1980). Oral phencyclidine (PCP) self-administration in rhesus monkeys: Effects of feeding conditions. Joumal of Pharmacology and Experimental Therapeutics, $214,339-346$.

Carroll, M.E., \& Meisch, R.A. (1984). Increased drug-reinforced behavior due to food deprivation. In T. Thompson, J.E. Barrett, \& P.B. Davis (Eds.), Advances in behavioral pharmacology (Vol. 4, pp. 47-88). New York: Academic.

Casper, R.C., Eckert, E.D., Halmi, K.A., Goldberg, S., \& Davis, J. (1988). Bulimia: Its incidence and clinical importance in patients with anorexia nervosa. Archives of General Psychiatry, 37, 10361040.

Crisp, A.H. (1968). Primary anorexia nervosa. Gut, 9, 370-372.

Drewnowski, A., Yee, D.K., \& Krahn, D.D. (1988). Bulimia in college women: Incidence and recovery rates. American Journal of Psychiatry, 145, 753-755.

Drewnowski, A., Yee, D.K., \& Krahn, D.D. (1989). Dieting and bulimia: A continuum of behaviors. San Francisco: American Psychiatric Association.

Eckert, E.D., Goldberg, S.C., Halmi, K.A., Casper, R.C., \& Davis, J.M. (1982). Depression in anorexia nervosa. Psychological Medicine, 12, 115-122.

Forsander, O.A. (1988). The interaction between voluntary alcohol consumption and dietary choice. Alcohol and Alcoholism, 23, 143-149.

Frank, R.E., Serdula, M., \& Abel, G.G. (1987). Bulimic eating behaviors: Association with alcohol and tobacco. American Journal of Public Health, 77, 369-370.

Franklin, J.C., Schiele, B.C., Brozek, J., \& Keys, A. (1948). Observations on human behavior in experimental semistarvation and rehabilitation. Joumal of Clinical Psychology, 4, 28-45.

Garfinkel, P.E., Moldofsky, H., \& Garner, D.M. (1980). The heterogeneity of anorexia nervosa. Archives of General Psychiatry, 37, 1036-1040.

Gosnell, B.A., \& Krahn, D.D. (1992). The relationship between saccharin and alcohol intake in rats. Alcohal, 9, 203-206.

Hanna, J.M., \& Hornick, C.A. (1977). Use of coca leaf in southern Peru: Adaptation or addiction. Bulletin on Narcotics, 29, 63-74.

Hatsukami, D.K., Eckert, E.D., Mitchell, J.E., \& Pyle, R.L. (1984). Affective disorder and substance abuse among women with bulimia. Psychological Medicine, 14, 701-704.

Heatherton, T.F., \& Baumeister, R.F. (1991). Binge eating as escape from self-awareness. American Psychological Association, 110, 86-108.

Hursh, S.R., \& Beck, R.C. (1971). Bitter and sweet saccharine preference as a function of food deprivation. Psychological Reports, 29, 419-422.

Jessor, R., \& Jessor, S.L. (1977). Problem behavior and psychosocial development: A longitudinal study for youth. New York: Academic.

Johnston, L.D., Bachman, J.G., \& O'Malley, P.M. (1990). Monitoring the future: A continuing study of the lifestyles and values of youth, 1989 [Computer file]. Ann Arbor, MI: Interuniversity Consortium for Political and Social Research. Conducted by University of Michigan, Survey Research Center.

Jonas, J.M., Gold, M.S., Sweeney, D., \& Pottash, A.L.C. (1987). Eating disorders and cocaine abuse: A survey of 259 cocaine abusers. Journal of Clinical Psychiatry, 48, 47-50.

Jones, D.A., Cheshire, N., \& Moorhouse, H. (1985). Anorexia nervosa, bulimia and alcoholism: Association of eating disorder and alcohol. Journal of Psychiatric Research, 19(2/3), 377-380.

Kandell, D.B., \& Logan, J.A. (1984). Patterns of drug use from adolescence to young adulthood: I. Periods of risk for initiation, continued use and discontinuation. American Journal of Public Health, 74, 660-666.

Killen, J.D., Taylor, C.B., Telch, M.J., Robinson, T.N., Maron, D.J., \& Saylor, K.E. (1987). Depressive 
symptoms and substance use among adolescent binge eaters and purgers: A defined population study. American Journal of Public Health, 77, 1539-1541.

Krahn, D.D., \& Gosnell, B.A. (1991). Fat-preferring rats consume more alcohol than carbohydratepreferring rats. Alcohol, 8, 313-316.

Leon, G.R., Carroll, K., Chernyk, B., \& Finn, S. (1985). Binge eating and associated habit patterns within college student and identified bulimic populations. International Journal of Eating Disorders, 4, 43-57.

Marcus, R.N., \& Halmi, K.A. (1989, May). Eating disorders in substance abuse patients. Paper presented at the American Psychiatric Association, San Francisco, CA.

Mitchell, J.E., Hatsukami, D., Eckert, E.D., \& Pyle, R.L. (1985). Characteristics of 275 patients with bulimia. American Journal of Psychiatry, 142, 482-485.

Pyle, R.L., Halvorson, P.A., Neuman, P.A., \& Mitchell, J.E. (1986). The increasing prevalence of bulimia in freshman college students. International Journal of Eating Disorders, 5, 631-647.

Pyle, R.L., Mitchell, J.E., \& Eckert, E.D. (1981). Bulimia: A report of 34 cases. Journal of Clinical Psychiatry, 42, 60-64.

Pyle, R.L., Mitchell, J.E., Eckert, E.D., \& Halvorson, P.A. (1983). The incidence of bulimia in freshman college students. International Journal of Eating Disorders, 2, 75-85.

Reed, D.R., Contreras, R.J., Maggio, C., Greenwood, M.R.C., \& Rodin, J. (1988). Weight cycling in female rats increases dietary fat selection and adiposity. Physiology and Behavior, 42, 389-395.

Rosen, J.C., \& Gross, J. (1987). Prevalence of weight reducing and weight gaining in adolescent girls and boys. Health Psychology, 6, 131-147.

Schotte, E.E., \& Stunkard, A.J. (1987). Bulimia vs. bulimic behaviors on a college campus. Journal of the American Medical Association, 258, 1213-1215.

Stewart, R.B., \& Grupp, L.A. (1984). A simplified procedure for producing ethanol self-selection in rats. Pharmacology, Biochemistry, and Behavior, 21, 255-258.

Striegel-Moore, R.H., Silberstein, L.R., Frensch, P., \& Rodin, J. (1989). A prospective study of disordered eating among college students. International journal of Eating Disorders, 8, 499-509.

Strober, M., Salkin, B., Burroughs, J., \& Morrell, W. (1982). Validity of the bulimia-restrictor distinction in anorexia nervosa. Journal of Nervous and Mental Disease, 170, 345-351.

Walsh, B.T. (1985). Bulimia and depression. Psychosomatic Medicine, 47, 123-131.

Weiss, S., \& Ebert, M. (1983). Psychological and behavioral characteristics of normal-weight bulimics and normal-weight controls. Psychosomatic Medicine, 45, 293-303. 